\title{
Research on the Construction of University Archives Information under the New Information Environment
}

\author{
Shumin $\mathrm{Cui}^{1, \mathrm{a}}$ \\ ${ }^{1}$ Management of Teaching and Research Base, Jilin Agricultural University, \\ Changchun,130118, China \\ ${ }^{a}$ cuishuminc126.com
}

Key words: University, File management, Information construction

\begin{abstract}
With the constantly changing in current education and teaching environment, colleges and universities are also paying more and more attention to file management. The major colleges and universities are constantly promoting the file management information construction. At present, there are still many problems in the informationization construction of archives management in colleges and universities, which seriously hinders the normal development of archives management information construction in colleges and universities. Only by summing up the analysis of the reasons and developing a targeted solution, can we promote the construction of university archives management information process fundamentally.
\end{abstract}

\section{Introduction}

Measures of Archives Management in Colleges and Universities (hereinafter referred to as the "Measures") shall be jointly issued by the Ministry of Education and the State Archives Bureau in the form of Decree No. 27 of the Ministry of Education of the People's Republic of China and was formally implemented on September 1, 2008. The Measures not only standardizes archives management work in university but also makes a clear request on the information construction of university archives management. The implementation of Measures will accelerate the information construction of university archives management and effectively promote the construction of archives information resources. It also promotes the construction of archives basic business which is of great practical significance to the healthy development of archives in colleges and universities.

\section{The Basic Connotation of Information Archives Service}

The development of the times depends not only on advanced technology, but also on the collection and adoption of information. And the collection and adoption of information is inseparable from the management of archives services. The 21st century is the era of talent and enterprises often use the method of querying and comparing their files and information when choosing talents. In the context of the rapid development of information technology, China's archives information service management work gradually steps into digital which means users can query the file information they want through the specific network system after the network preservation of the traditional paper information through the processing and scanning. This method is simple to operate and quick to get information. It can also provide users with a very convenient service with a strong pertinence. The above is the basic connotation of university archives services under the background of rapid development of information and also the new method for colleges and universities to carry out strategic reform ${ }^{[1]}$.

\section{The Necessity and Significance of Digitalization of Archival Information}

From the university level, the digital construction of archival information is an inevitable trend of campus office automation. With the continuous improvement of the level of office automation, paperless office background will produce a lot of digital information and CD-ROM, disk and other dependent storage carrier, and the formation of a variety of dynamic digital file information. The 
digitization of the archives can save the archival information of different carriers in the form of united digital standard and realize the rapid spread and convenient use of sharing of the archival information resources, which greatly reduces the work intensity of manual labor.

From the archives information processing level, the archives information digital construction work is conducive to the spread and sharing of all kinds of file information resources. With the deepening degree of social information, archives information resources have been highly concerned and of growing demand for use. Its value is also increasingly apparent. Digitization of file information is conducive to quick retrieval and multi-directional delivery. Users can query the required file information at any time as long as there is a certain authority and as long as the place is of network coverage, which can greatly save manpower, material and time ${ }^{[2]}$.

From the file management level, the digital information is the inevitable result of strengthening the modern management of archives. Files in colleges and universities are increasing every year and the storage room of archives is reducing in space. A variety of carrier forms of archives occupy a lot of space. The traditional file management can not meet the needs of users and the digital construction of archival information comes into being. Digital archives can be reserved and obtained in a tremendous amount. It saves the management costs and using costs of archives information resources economically. It also saves the network space and real space of archive reservation and reduces the pressure of archives and the storage situation of archives information resources of network space. Therefore, the file digitization is to adapt to the reform and development of education and follow the social development for archives management. Speed up the digital construction of archives and make the university archives management work better serve the community ${ }^{[3]}$.

\section{Problems in the Current Archives Management of Colleges and Universities}

\subsection{Backward methods and unclear awareness}

Many university leaders will focus on the work of teaching and scientific research, while ignoring the importance of other work, which has a negative impact on the school's construction. And they are also unable to put enough emphasis on file management work. The important position of file management can only be realized when archives resource is needed, which hinders the function of archives management and is not conducive to the development of other work in colleges and universities.

\subsection{Inadequate professional quality of administrator}

Many colleges and universities consider archives as a department to solve the employment of talented families. Although it can alleviate the problem of social employment to a certain extent to arrange the families of talents in the archives, their physical condition and cultural level are not fully taken into account, which is not conducive to the development of university archives management. The current college full-time file management staff gradually appear the phenomenon of aging and many people do not have the computer and network technology and other related technologies. Today's continuing technology development will inevitably eliminate the backward university archives management model ${ }^{[4]}$.

\subsection{Incomplete file function}

In the archives of colleges and universities, large amount of and relatively rich archives information is preserved. But administrators are not fully aware of the significance of these archives resources. Then the efficiency of using archives resources is difficult to improve. Some college teachers and students fail to pay enough attention to the management of archives and many people hold the view that file management is useless and are indifferent to the school archives work. The current archives approach in university fails to follow the trend of the development of archives and 
cannot make full use of archives resources. Other functions of archives in some colleges and universities are also insufficient. The needs of teachers and students cannot be satisfied by only taking it as a tool for file management and preservation.

\section{Effective Strategies of Archives Informatization Construction in Colleges and Universities}

The construction of archives information standard is the basis for the construction of archives information in colleges and universities and also the basis for improving the level of the construction of archives information in colleges and universities. University archives management department can carry out the construction of archives information standard and standardize the formation and archiving of electronic document and marking, description, storage, query, handover, online transmission and management of electronic file information resource by combining the actual situation of archives management in colleges and universities and the relevant national regulatory documents such as electronic file filing and management, $A D$ electronic file $C D$ storage, archiving and file management requirements, technical specifications of digital paper file, education management information standards, and so on.

Archives information resource construction is the core of archives information construction in colleges and universities. Archives information resource construction mainly includes two parts: digitalization of the existing collections and integrated information resources. Digitalize the traditional carrier files and scan documents, drawings, photos and other paper files. Conduct analog-to-digital conversion on the tape and other audio and video data and conduct digital shooting to physical file. File directory digitalization refers to the construction of the file directory database. Input the subject, category, former, the formation of time and other entries and form machine-readable directory to enable users find the required files quickly and accurately through the computer network. Under the trend of sharing digital construction of resources, it is necessary to integrate the relatively independent resource system among the departments within the school and implement a unified information resources construction standard. It can be ensured that the resource system can be docked with the file management system to achieve the simultaneous archiving of the traditional carrier files and electronic information resources ${ }^{[5]}$.

The construction of archives management talent team is the key to the construction of archives information in colleges and universities. Archivist is the practitioner of archival information construction and is the producer and operator of archival information products. The level of managerial ability and quality determines the quality of archival information construction. Introduce specialized personnel of information technology, enhance training efforts, and cultivate compound talents. Build incentive mechanism to ensure the stability of the file management team.

The construction of security system is the guarantee of archives construction in colleges and universities. With the file information construction continues to advance, information security issues become more prominent. Other efforts are futile if there is no effective safety management. (1) Strict confidentiality system. Develop strict confidentiality system in accordance with the file secret system. Keep secret for those shouldn’t be seen, remembered and said. (2) Safe information data. Adopt the coexistence of traditional carrier and digital carrier for each file. Take multiple backup, remote backup and other methods on digital file information. Use the secret key to implement strict rights management to ensure the safety of information data. (3) Guarantee the security of system, network. Deploy anti-virus software, firewall and monitor the preventing viruses and network hacker intrusion. Regularly upgrade and check vulnerabilities. Resolve potential problems in time. Implement user authentication, control network access strictly, and prohibit users from overriding unauthorized actions. (4)Develop information security contingency plans. Once there appear information security problems, start quickly so that the file information system can return to normal in the shortest possible time and the information security hazards can be minimized to the largest extent. 


\section{References}

[1] Lu Changlan. Research on the Construction of Archives Management Informatization in Colleges and Universities. [J]. China Management Informationization, 2014（1）.

[2] Liang Jianmei. Misunderstandings and Countermeasures of Archives Construction in Colleges and Universities. [J]. Lantai World, 2014 (1).

[3] Gao Li. Thoughts on the Construction of Archives Information in Colleges and Universities. [J]. Vocational Education, 2011（5）.

[4] Wang Weiping. Analysis on the Influencing Factors of Archives Construction in Colleges and Universities and the Corresponding Strategies of Promotion. [J]. Journal of Xinxiang University, 2014 (7).

[5] Sun Yanli. Analysis on the Influencing Factors and Countermeasures of Archives Construction in Colleges and Universities. [J]. Information Science, 2012 (2). 